Sharif University of Technology
Scientia Iranica
SCIENTIA
IRANICA
Transactions A: Civil Engineering
www.scientiairanica.com

\title{
Dust detection and AOT estimation using combined VIR and TIR satellite images in urban areas of Iran
}

\author{
S. Sehatkashani ${ }^{\mathrm{a}}$, M. Vazifedoust ${ }^{\mathrm{b}, *}$, Gh. Kamali ${ }^{\mathrm{a}}$ and A.A. Bidokhtic \\ a. Department of Meteorology, Science and Research Branch, Islamic Azad University, Tehran, Iran. \\ b. Department of Water Engineering, Faculty of Agricultural Sciences, University of Guilan, Guilan, Iran. \\ c. Institute of Geophysics, University of Tehran, Tehran, P.O. Box 14155-6466, Iran.
}

Received 14 February 2015; received in revised form 1 August 2015; accepted 10 February 2016

KEYWORDS
Dust;
Synoptic systems;
Urban;
BTD;
MODIS;
AOT.

\section{Introduction}

Dust storms have significant impacts on the atmospheric system of earth. The mineral dust particles can alter the atmospheric heating and stability, influence the chemical and biological ecosystems, and affect the air quality and human health [1]. Dust particles may either absorb or scatter radiation, resulting in radiative forcing and remarkable reduction in visibility $[2,3]$.

\footnotetext{
*. Corresponding author. Tel.: +9813 336904859 ; Fax: +98133369028

E-mail addresses: saviz.sehat@srbiau.ac.ir (S.

Sehatkashani); majid.vazifedoust@yahoo.com (M. Vazifedoust); a.kamali@srbiau.ac.ir (Gh. Kamali); bidokhti@ut.ac.ir (A.A.Bidokhti)
}

Radiative forcing due to dust aerosols is one of the largest sources of uncertainties in global and regional climate change. Thus, identifying physical (size and shape) and chemical (composition and mineralogy) characteristics of dust aerosols is the first step in understanding the effects of dust aerosols in climate change research [4-6]. The volume size distribution, Single Scattering Albedo (SSA), and asymmetry parameter (g) are mainly used to study the physical dust characteristics [7]; however, measurement of these parameters is not always possible in many cases. Instead, physical dust characteristics are determined by optical properties (dust optical thickness (AOT) and Visibility Reduction (VR)), which vary spatially and temporally [8]. The variability of optical properties 
is mainly controlled by aerosol in the atmosphere [9]. The heterogeneous mixture of dust aerosols causes the considerable uncertainties in quantifying the impact of dust on regional and global climate [10]. Optical properties have been described in several studies using satellite remote sensing and ground observations [11$13]$.

Satellite Remote sensing technology is much more effective in dust detection and analysis of the optical properties than traditional ground-based observations that are restricted by many factors, e.g. insufficient number of observing instruments and stations, time consuming, and high survey costs [14]. There are principally two different methods for dust detection using satellite measurements: active and passive methods. These include the visible and infrared (VIR) method, thermal infrared (TIR) method, Microwave Polarized Index (MPI) method, active lidar-based method, and Combined Lidar and Infrared Measurement (CLIM) method [15]. However, for operational purposes, passive methods are preferred and are more common. Terra/Aqua MODIS true-color image is commonly used for identifying dust transport direction. MODIS dust indices, Brightness Temperature Difference (BTD) [16], and Normalized Difference Dust Index (NDDI) [17] are used for dust detection and analysis of its optical properties. Using Brightness Temperature Differences (BTDs) between 8 and $11 \mu \mathrm{m}$, and the $11-$ and $12-\mu \mathrm{m}$ channels, dust can be detected under clear sky over both ocean and land. The infrared (IR) BTD method is very effective in the detection of dust storms [18-20]. The NDDI was proposed by Qu et al. [17] as a result of strong discrimination between dust reflectance and water or ice clouds in the 2.13and $0.469-\mu \mathrm{m}$ bands. However, it is difficult for a non-expert to understand the real intensity from these indices, because these indices include much noise, such as ground surface influence. To avoid unnecessary information, a comprehensible dust index is required for dust extraction process.

In this paper, a novel passive method based on the visible and infrared (VIR) and thermal infrared (TIR) satellite measurements is presented and evaluated for dust detection, estimation of aerosol optical thickness, and visibility reduction over lands. This study has been carried out using measurements from ground based instruments and satellite observations during an extreme dust event in July from 5 to $6,2009$.

\section{Methodology}

\subsection{Dust indices}

Dust storms are a common phenomenon in the southwestern part of Iran during the warm (May-Sept.) season [21-23]. The western part of Iran has periodically experienced a dust outflow in warm seasons, which are transported by westerly winds from the western and the south-western (Arabian countries) regions. In order to investigate the feasibility of dust indices (NDDI, BTD, and TDI) for duct detection, and extraction of optical properties (optical thickness and visibility reduction), dust events originating from Middle East region in dry season were studied. MODIS/Terra calibrated radiance products of MOD02QKM (250 m), MOD02HKM $(500 \mathrm{~m})$, and MOD021km (1 km) corresponding to dust event dates, which were ordered and downloaded to be used in producing dust indices. MODIS product (MOD08D3) of Aerosol Optical Depth (AOD) was used in the evaluation process of the estimated AOT.

Hourly meteorological data of wind speed and visibility were collected from all synoptic weather stations to investigate the frequency of dust occurrences and visibility reduction during dust events. To evaluate accuracy of the proposed equation for AOT, ground based AOT data from Air Quality Control (AQC) was also collected. Figure 1 shows the study area consisting of 35 synoptic stations over west and south-west of Iran.

\section{Normalized Difference Dust Index (NDDI)}

NDDI is the difference between reflectance in $2.13 \mu \mathrm{m}$ and that in $0.469 \mu \mathrm{m}$. NDDI, as a visible and infrared (VIR) dust index, was derived from spectral signature of dust particles as follows:

$$
\begin{aligned}
\mathrm{NDDI}= & (\rho 2.13 \mu \mathrm{m}-\rho 0.469 \mu \mathrm{m}) / \\
& (\rho 2.13 \mu \mathrm{m}+\rho 0.469 \mu \mathrm{m}),
\end{aligned}
$$

where $\rho 0.469 \mu \mathrm{m}$ and $\rho 2.13 \mu \mathrm{m}$ are reflectances in the $0.469-$ and $2.13-\mu \mathrm{m}$ bands, respectively [17].

\section{Brightness Temperature Difference (BTD)}

The BTDs between the 8- and $11-\mu \mathrm{m}$, and the 11- and $12-\mu \mathrm{m}$ channels are sensitive to dust loading and hence feasible to be used for dust outbreak tracking [16]. Since the brightness temperature over dust at the 12 $\mu \mathrm{m}$ channel is greater than that at the $11-\mu \mathrm{m}$ one, the BTD is negative over dust plume. The brightness temperature was derived from inverse of the Planck equation by wavelength $\lambda$ and radiance $I_{\lambda}$ of each channel and BTD index was then calculated as follows:

$$
\begin{aligned}
& \mathrm{BTD}=\mathrm{BT}_{8 \mu \mathrm{m}}-\mathrm{BT}_{11 \mu \mathrm{m}}, \\
& \mathrm{BTD}=\mathrm{BT}_{11 \mu \mathrm{m}}-\mathrm{BT}_{12 \mu \mathrm{m}} .
\end{aligned}
$$

\section{Thermal infrared Dust Index (TDI)}

It is found that AOT at $550 \mathrm{~nm}$ has close relationships with the brightness temperature of MODIS bands 20, 30,31 , and 32 . TDI has advantages of high spatial resolution, potential for nighttime dust detection, and indication of dust intensity as a result of good matching with MODIS AOT at $550 \mathrm{~nm}[24,25]$. It can be 


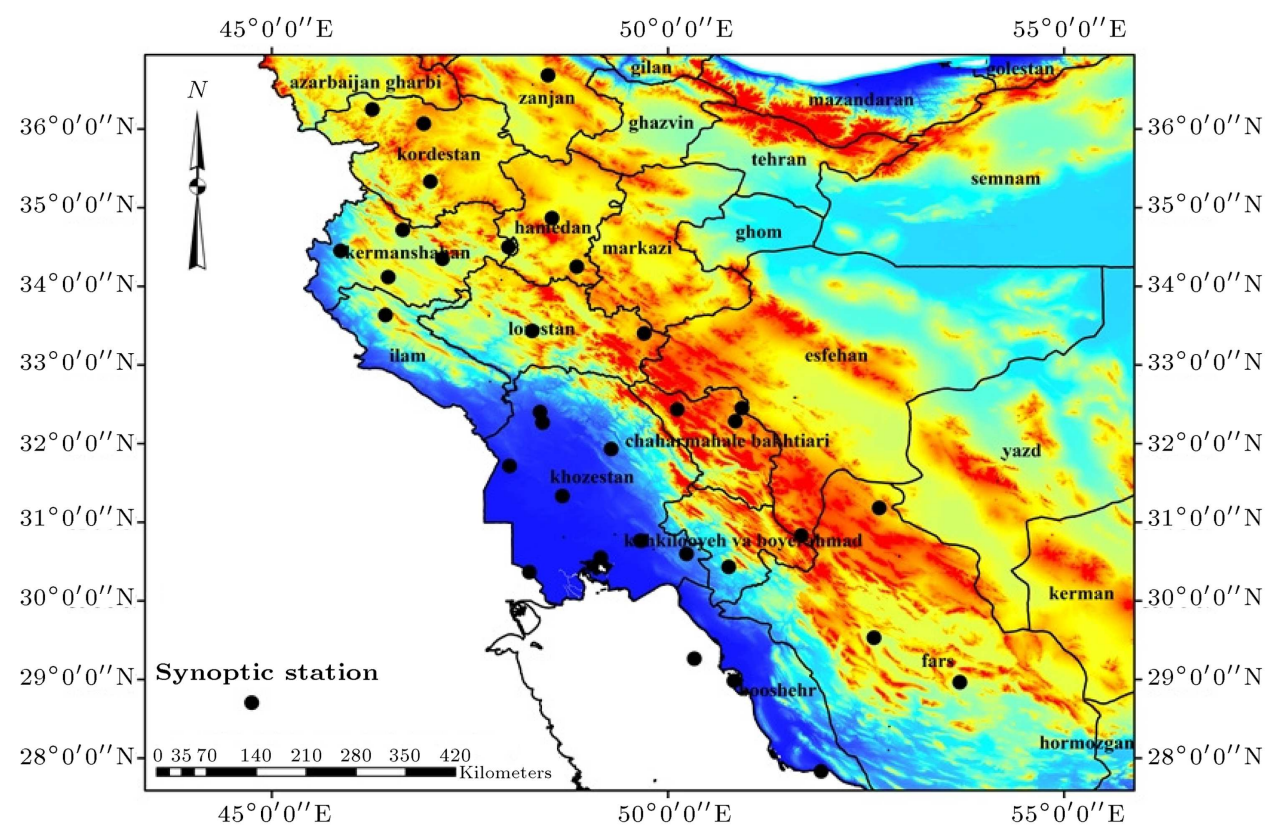

Figure 1. The location of synoptic meteorological stations used in this study.

used as a proxy variable for estimating dust intensity and separating Saharan dust storm with background aerosol. TDI was introduced as follows:

$$
\begin{aligned}
\text { TDI }= & c 0+c 1 * B T 20+c 2 * B T 30+c 3 * B T 31 \\
& +c 4 * B T 32,
\end{aligned}
$$

where, c0, c1, c2, c3, and c4 are constant coefficients as $-7.93,0.123,0.026,-0.7068$, and 0.588 , respectively.

\subsection{Verification of AOT and visibility reduction}

Visibility reduction was obtained by fitting a multiregression equation based on dust indices (NDDI and BTD) derived from MODIS data and visibility data from 24 out of 35 synoptic weather stations on July 5 and 6, 2009. The proposed AOT equation was obtained by fitting a multi-regression equation based on NDDI, BTD, and MODIS AOT products over the selected synoptic weather stations. Data from the remained stations (11 synoptic stations) was applied for the validation process. The accuracy of estimated AOT was evaluated using ground based AOT data from AQC stations.

\section{Results and discussion}

\subsection{Frequency and distribution of dust events}

Figure 2(a) shows the distribution of dust frequencies in the south-western Iran $\left(45-54^{\circ} \mathrm{E}, 27-37^{\circ} \mathrm{N}\right)$. It reveals that the intensity of the most frequent suspended dust events (those that cause visibility reductions of less than $1000 \mathrm{~m}$ ) is found in the west and south-west of Iran, decreasing from west to east across the region.

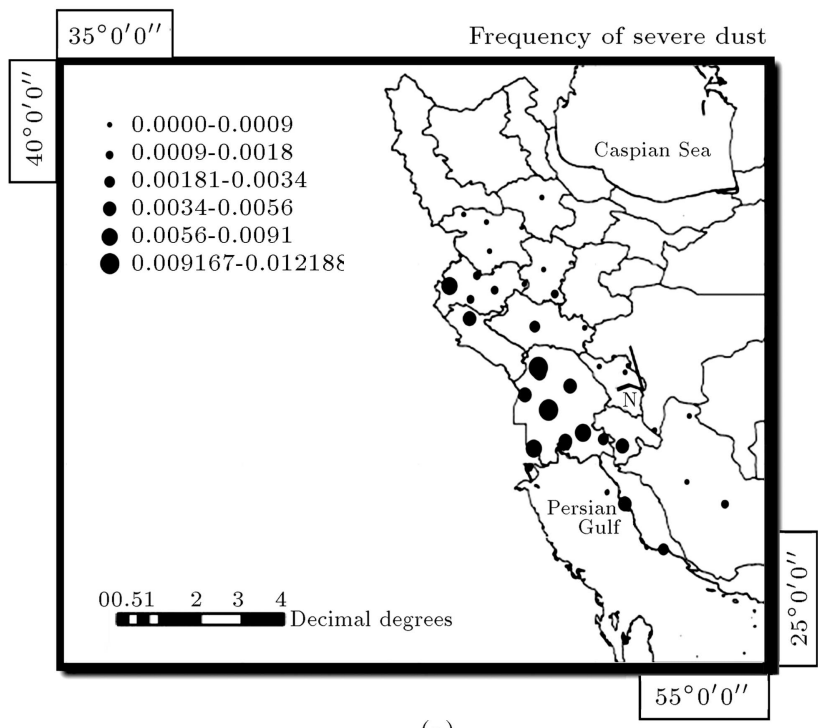

(a)

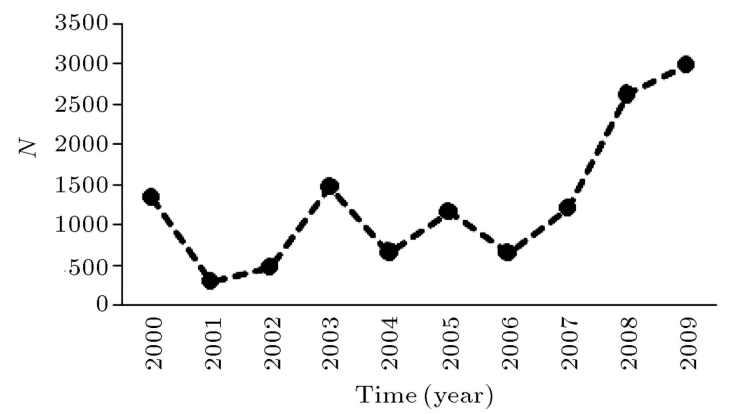

(b)

Figure 2. (a) Distribution of dust frequency causing visibility reduction less than $1000 \mathrm{~m}$ and (b) annual total number of dust days, $N$, reported from national synoptic meteorological stations of west and south-west of Iran for 2000-2009. 
There are 35 national synoptic meteorological stations with continuous observations in dust-affected areas of west and south-west of Iran. By calculating the total number of suspended dust days reported from all stations as $N$, the dust variability is evaluated for the period 2000-2009. Figure 2(b) indicates that there have been increasing trends in suspended dust event frequency in west and south-west of Iran during the years 2001-2003 and 2006-2009. In addition, the year 2001 with 297 records of accumulative suspended dust has the least frequency, while the year 2009 with 2982 records of accumulative suspended dust has the most frequency [21]. From the synoptic point of view, it can be concluded that Shamal systems severely reduce the visibility at the surface. The synoptic feature that creates the potential for the summer Shamal is a zone of convergence between the subtropical ridge, extending into the northern Arabian Peninsula and Iraq from the Mediterranean Sea, and the Monsoon Trough across southern Iran and the Southern Arabian Peninsula. Better understanding of climatology of dust events could lead to more precise dust forecasting with positive economic effects.

\subsection{Evaluation of VIR and TIR based dust indices for dust detection}

In order to evaluate the feasibility of VIR and TIR based dust indices in dust detection, an extreme dust event on July 5 to 6, 2009 was analyzed. Figure 3 indicates an overview of two true-color composition images that belong to these extreme dust events. NDDI as VIR index, BTD as TIR index, and TDI as combined index were derived from MODIS satellite images. To detect dust using NDDI, the ranges of NDDI values

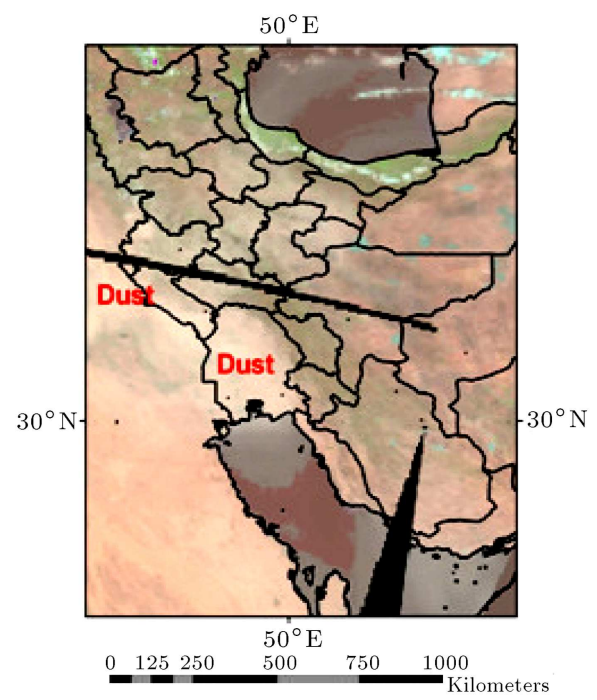

(a) over the land covered by dust were analyzed and the thresholds were determined. Figure 4(a) and (b) show maps of NDDI for both days (July 5 and 6, 2009). Red color in these maps indicates dust area and yellow color indicates no-dust area. For clouds, reflectance at the $0.469-\mu \mathrm{m}$ band was higher than the reflectance of the $2.13-\mu \mathrm{m}$ band and NDDI value was negative. NDDI values of dust plume over land varied in the range of 0.19 to 0.28 . Thus, it is concluded that dust plume over lands can be separated from other clouds and land with dark background as well. However, due to similarity of spectral signatures, detection of dust plume over land with bright background was almost impossible using only NDDI. Since suspended sand and dust particles were cooler than sand and dust particles on the ground, a threshold value of $278 \mathrm{~K}$ was used to separate airborne dust from ground sand and dust in the area with bright background (Figure 4). Comparing NDDI values of dust pixels with ground station visibility data over synoptic stations indicated a good correlation. However, increasing visibility with NDDI shows that NDDI cannot be a true indicator for dust enhancement in the area with bright surface (Figure 4(c)).

To detect dust plume using BTD index, brightness temperatures in 11- and $12-\mu \mathrm{m}$ bands were derived from MODIS thermal bands (bands 31 and 32) and BTD maps were produced for both days (Figure 5(a) and (b)). Dust area (red color) was separated by specifying threshold values over dust pixels. By comparing BTD values over dust and cloud pixels, it was observed that subtracting the BT value in band 31 from that in band 32 resulted in the value $<-0.5 \mathrm{~K}$, which demonstrated the presence of mineral dust while the value $>0$ $\mathrm{K}$ indicated non-mineral aerosol. As shown in Figure 5,

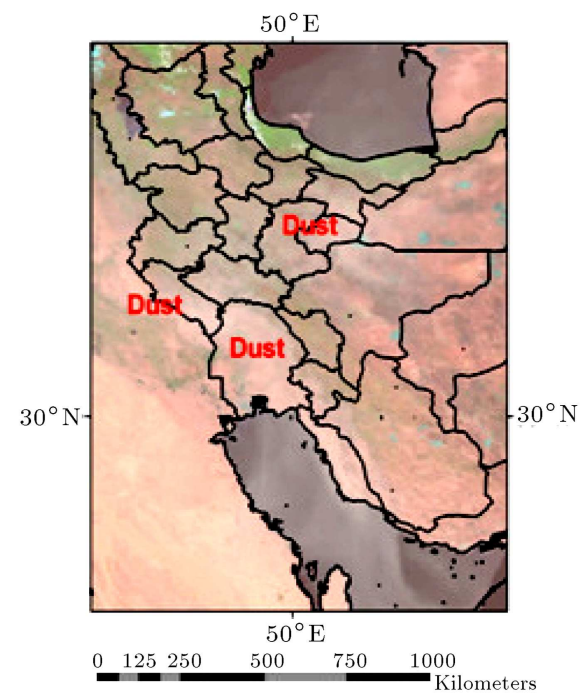

(b)

Figure 3. Detection of an extreme dust event on July 5 and 6, 2009: (a) MODIS true-color image (July 5, 2009); and (b) MODIS true-color image (July 6, 2009). 


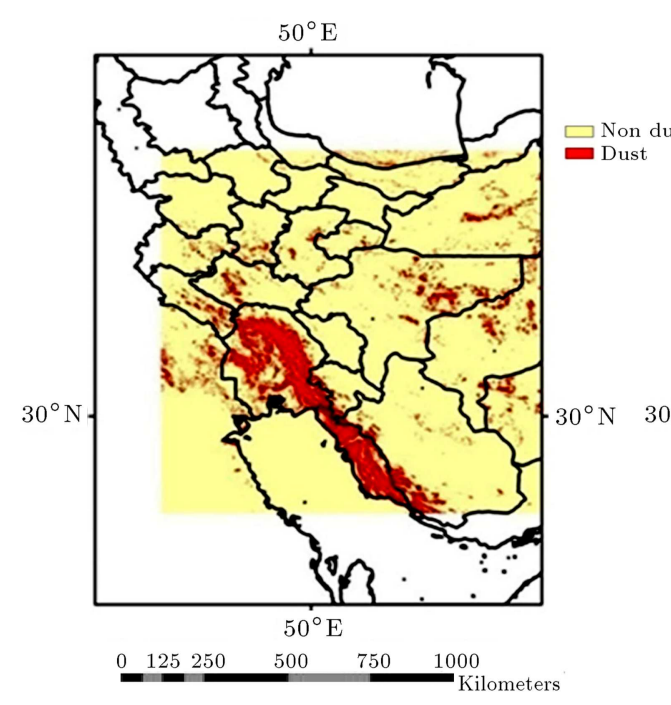

(a)

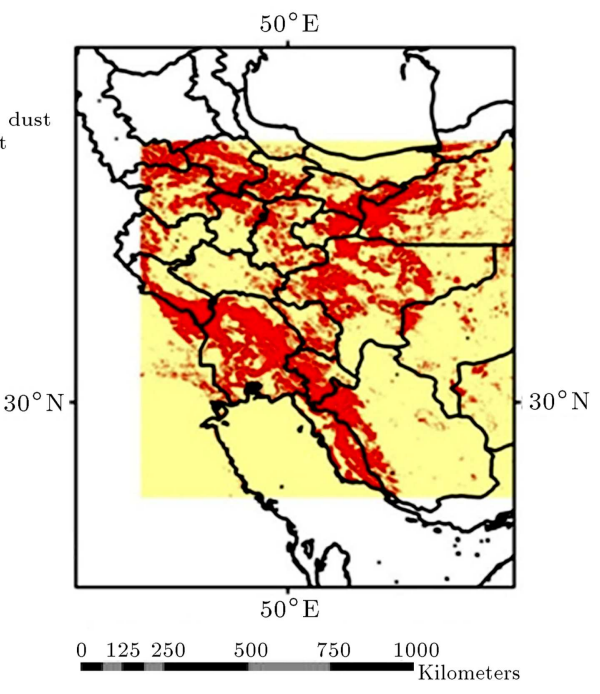

(b)

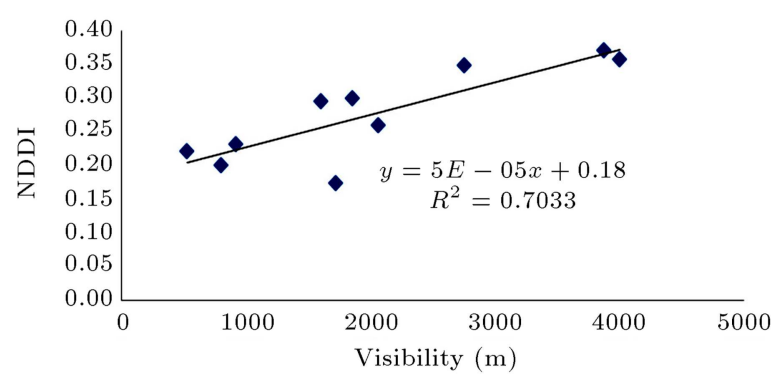

(c)

Figure 4. Detection of an extreme dust event on July 5 and 6, 2009 using Normalized Difference Dust Index (NDDI) and comparison of dust index with visibility over 11 synoptic stations: (a) NDDI image (July 5, 2009); (b) NDDI image (July 6, 2009); and (c) NDDI vs. visibility.

BTD index demonstrates high potential in detection of dust pattern over vast geographic area with bright to dark background. Comparing BTD values with ground visibility data over synoptic stations indicated their better performance in separating dust from bright surfaces and clouds than NDDI (Figure 5(c)). However, still some bright surfaces have been considered as dust pixels.

To reduce the uncertainty in identifying dust pixels over bright surfaces, a combined index based on both NDDI and BTD was implemented in dust detection as Thermal infrared Dust Index (TDI). By comparing TDI values over dust and cloud pixels, the threshold of TDI values for dust detection was identified and dust maps were produced. As shown in Figure 6(a) and (b), TDI was successful in dust detection over bright to dark background; noise was removed and thick dust was separated from normal dust (considering TDI $\geq 5.1 \mathrm{~K}$ ). The proposed TDI index matches visibility data very well with correlation coefficient of 0.745 (Figure 6(c)). This result confirmed that implementation of both solar reflective bands and thermal emissive bands would improve dust detection and reduce uncertainties.

\subsection{AOT and visibility reduction}

As shown in Figure 7, the evaluation of dust events revealed the remarkable correlation of AOT with dust enhancement indices over 24 synoptic stations. Hence, empirical equations for AOT and visibility reduction were obtained by fitting multi-regression equations based on NDDI and BTD values over randomly selected stations (24 out of 35 synoptic stations) as follows:

$$
\mathrm{AOT}=1.86446+0.337196 * \mathrm{BTD}-3.55592 * \mathrm{NDDI},
$$

Visibility $=2217.46+1479.4 * \mathrm{BTD}+6844.46 *$ NDDI.

AOT data from the proposed method indicated a good correlation with dust indices including BTD $(R 2=0.73)$, TDI $(R 2=0.71)$, and NDDI $(R 2=$ 0.67 ), respectively (Figure 7 ). As shown in Figure 7 , increase in TDI and BTD is accompanied by increase in AOT. However, decline of AOT with increase in NDDI indicates uncertainty in using NDDI. Therefore, both BTD and NDDI have been implemented in the extension of the proposed equations. As shown in 


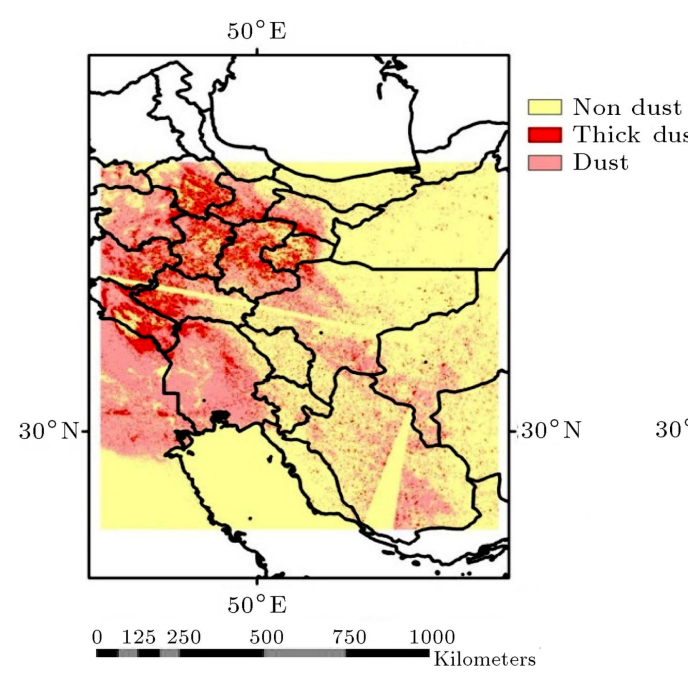

(a)

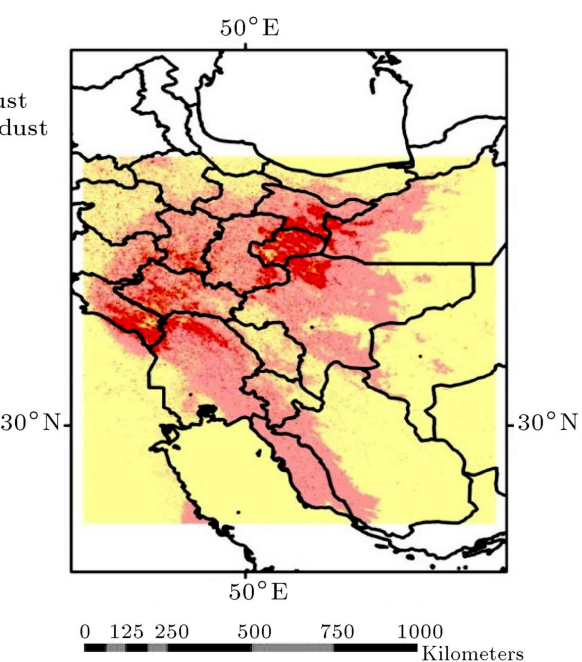

(b)

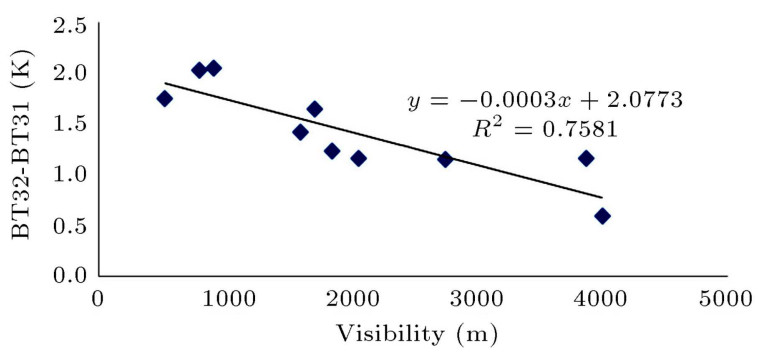

(c)

Figure 5. Detection of an extreme dust event on July 5 and 6, 2009 using Brightness Temperature Difference (BTD) and comparison of dust index with visibility over 11 synoptic stations: (a) BTD image (July 5, 2009); (b) BTD image (July 6, 2009), and (c) BTD vs. visibility.

Figure 8(a), results of the proposed AOT well match MODIS AOT products at $550 \mathrm{~nm}(R 2=0.74)$ as well as visibility data in range of 1000 to $2000 \mathrm{~m}(R 2=0.61)$ (Figure 8(b)). To evaluate accuracy of the proposed AOT equation, estimated AOT has been compared with reported AOT by 15 AQC stations. The results indicate good correlation $(R 2=0.74)$ between both estimated and measured AOT data (Figure 9(a)). The trends of both estimated and measured AOTs are the same and correspond with each other (Figure 9(b)).

Comparing the results of dust enhancement using both dust indices and the proposed AOT on July 5, 2009 confirmed the advantage of the proposed AOT as a consistent criterion for dust enhancement over bright surfaces as well as dust classification (Figure 10).

\section{Conclusion}

This paper examined a dust enhancement method using multiple MODIS thermal IR bands and solar reflective bands over the west and south-west of Iran during an extreme dust event. BTD and NDDI as TIR and VIR methods had the advantage of differentiating dust from non-mineral aerosols, while TDI as combined TIR and VIR method could detect dust over bright- reflecting source regions more precisely and discriminated between airborne dust and landmass. The results indicated that solar reflective bands were insufficient to precisely separate dust from other features, but combination of solar reflective bands and thermal infrared bands synergistically improved the accuracy of dust detection over bright surfaces.

The results revealed the remarkable correlation of AOT with dust enhancement indices: BTD $(R 2=$ $0.73)$, NDDI $(R 2=0.67)$, and TDI $(R 2=0.71)$. Hence, AOT and visibility reduction were obtained using multi-regression equations based on NDDI and BTD as variables. The accuracy assessment indicated good correlation $(R 2=0.74)$ between both estimated AOT and the AOT reported by Air Quality Control stations. Moreover, the results confirmed the advantage of the proposed AOT as a consistent index for dust enhancement over bright surfaces and dust classification as well.

\section{Acknowledgement}

The authors would like to express their profound sense of gratitude to NASA for providing meteorological satellite products. 


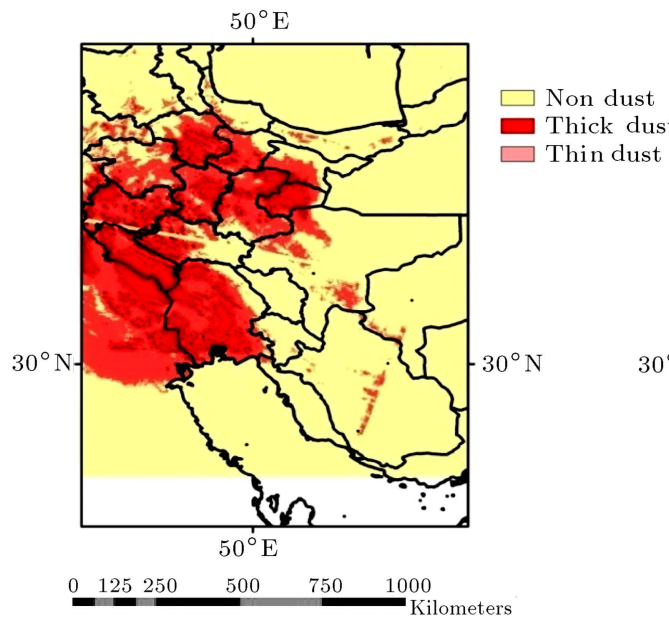

(a)

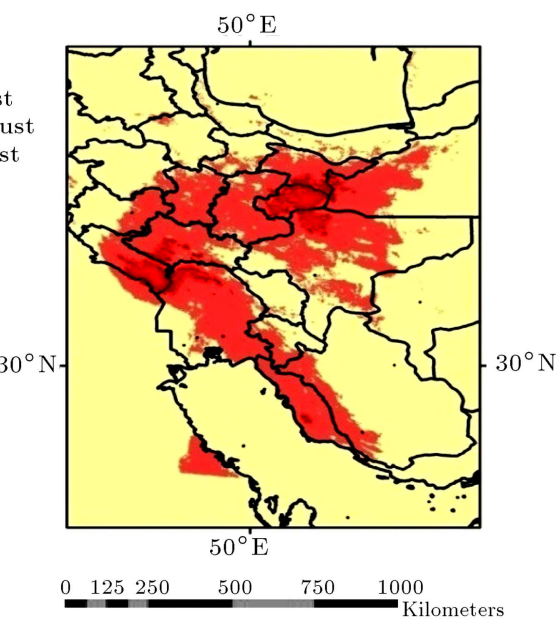

(b)

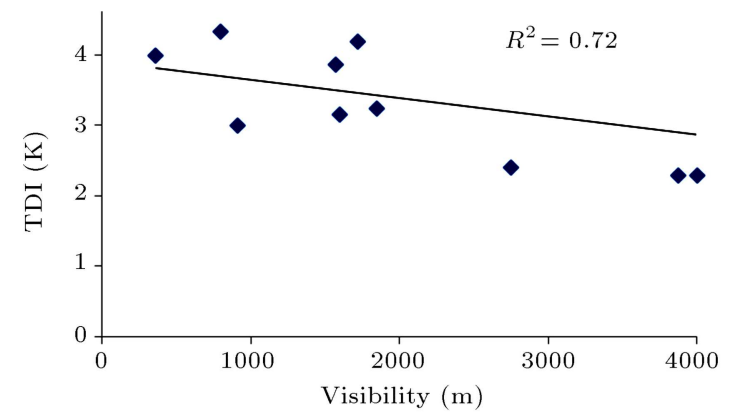

(c)

Figure 6. Detection of an extreme dust event on July 5 and 6, 2009 using Thermal Infrared Dust Index (TDI) and comparison of dust index with visibility over 11 synoptic stations: (a) TDI image (July 5, 2009); (b) TDI image (July 6, 2009); and (c) TDI vs. visibility.

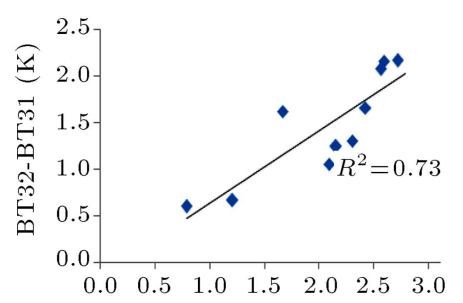

(a)

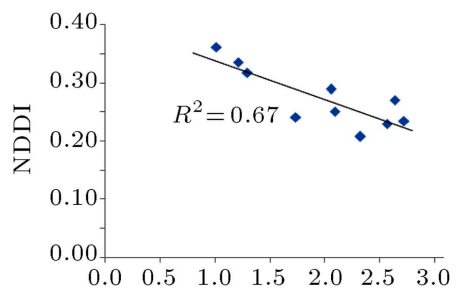

(b)

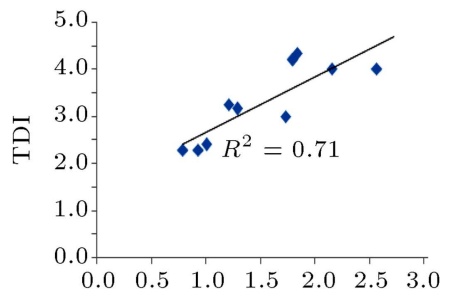

(c)

Figure 7. Comparison of dust indices with Aerosol Optical Thickness (AOT) over 11 synoptic stations: (a) NDDI vs. AOT; (b) BTD vs. AOT; and (c) TDI vs. AOT.

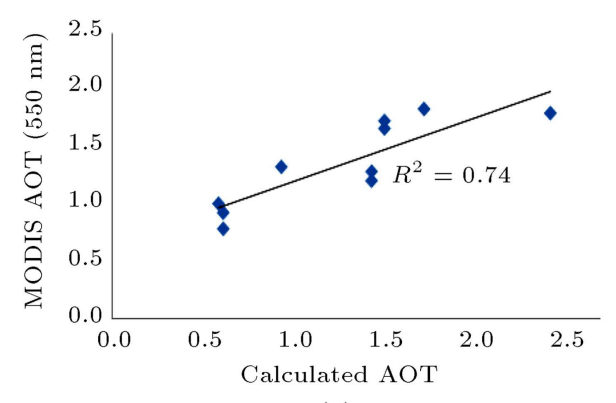

(a)

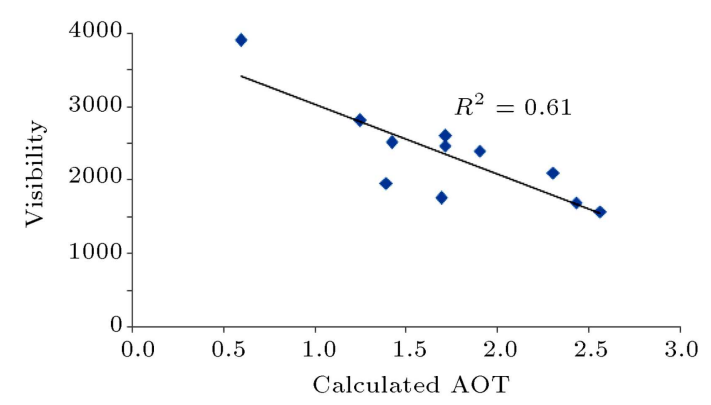

(b)

Figure 8. Comparison of Aerosol Optical Thickness (AOT) from proposed method with visibility and MODIS AOT product over 11 synoptic stations: (a) The empirical AOT vs. MODIS AOT (550 nm); and (b) the empirical AOT vs. $1000 \mathrm{~m}<$ visibility $<2000 \mathrm{~m}$. 


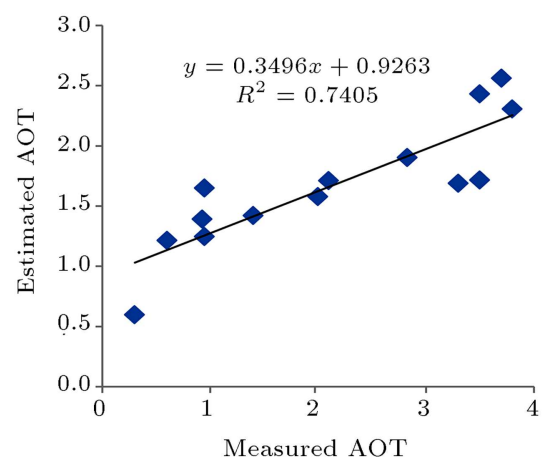

(a)

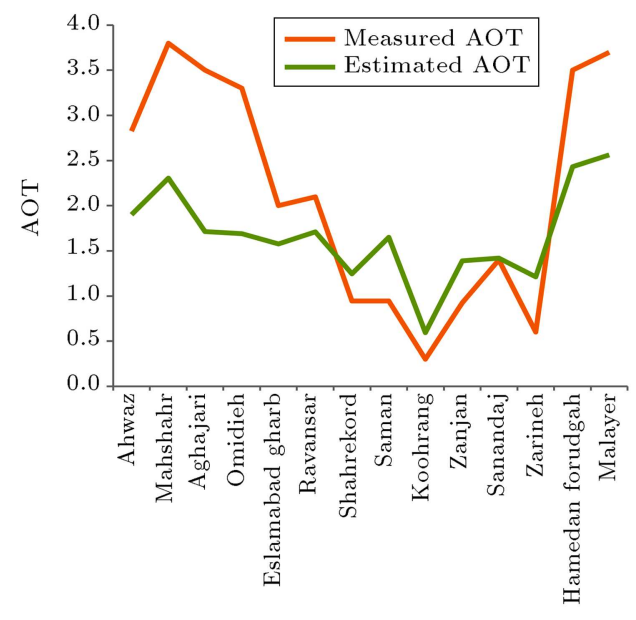

Measured AOT

(b)

Figure 9. Comparison of Aerosol Optical Thickness (AOT) from proposed method with measured AOT from 15 air quality control stations: (a) The empirical AOT vs. measured AOT (correlation); and (b) the empirical AOT vs. measured AOT (trend).

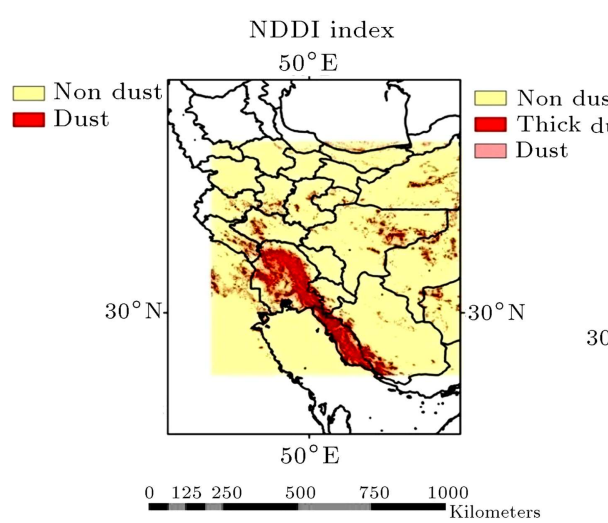

(a)

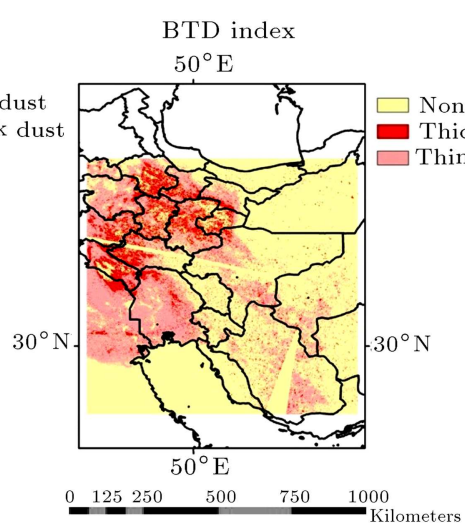

(b)

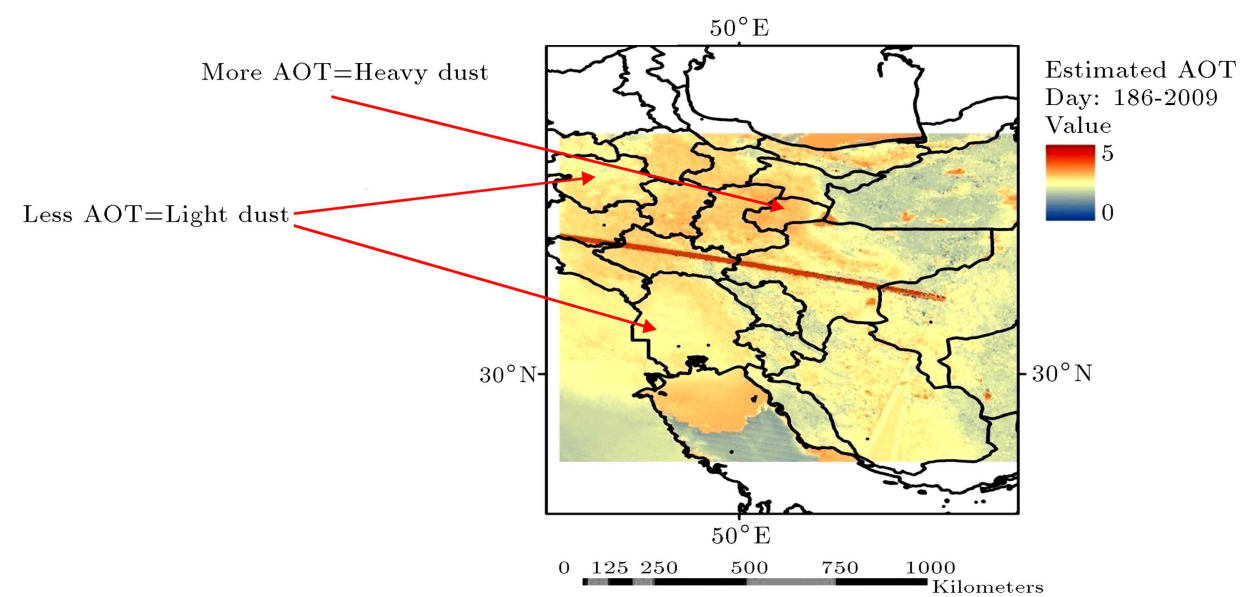

(d)

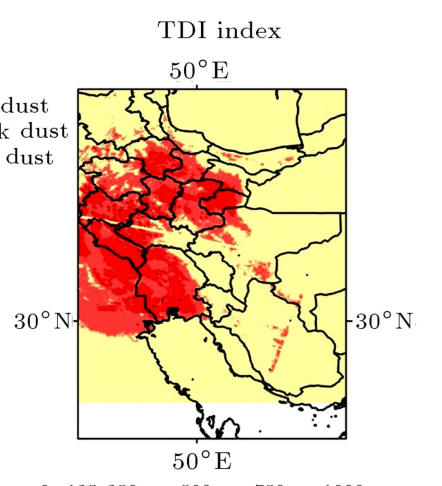

(c)

Figure 10. Dust enhancement using dust indices and proposed AOT on July 5, 2009.

\section{References}

1. Khan, A., Trautmann, T., Blaschke, T. and Fazli, S. "Changes in aerosol optical properties due to dust storms in the Middle East and Southwest Asia", Remote Sens. Environ., 143, pp. 216-227 (2014).
2. Tsoar, H. and Pye, K. "Dust transport and the question of desert loess formation", Sedimentology, 34, pp. 139-153 (1987).

3. Gao, Y., Fan, S. and Sariento, J.L. "Aeolian iron input to the ocean through precipitation scavenging: A 
modeling perspective and its implications for natural iron fertilization in the ocean", J. Geophys. Res., 108(7), pp. 4221-4232 (2003).

4. Wang, H., Shi, G. and Li, W. "The impacts of optical properties on radiative forcing due to dust aerosol", Adv. Atmos. Sci., 23, pp. 431-441 (2006).

5. Wang, H., Zhang, X., Gong, S., Chen, Y., Shi, G. and $\mathrm{Li}$ W. "Radiative feedback of dust aerosols on the East Asian dust storms", J. Geophys. Res., 115, D23214 (2010). DOI: 10.1029/2009JD013430.

6. Zhang, K. and Gao, H. "The characteristics of Asian dust storms during 2000-2002: from the source to the sea", Atmos. Environ., 41, pp. 9136-9145 (2007).

7. Patel, P.N. and Kumar, R. "Estimation of aerosol characteristics and radiative forcing during dust events over Dehradun", Aerosol. Air Qual. Res., 15, pp. 20822093 (2015).

8. Seinfeld, J.H., Carmichael, G.R., Arimoto, R. et al. "ACE-ASIA: regional climatic and atmospheric chemical effects of Asian dust and pollution", Bull. Am. Meteorol. Soc., 85, pp. 367-380 (2004).

9. Tegen, I. and Lacis, A.A. "Modeling of particle size distribution and its influence on the radiative properties of mineral dust aerosol", J. Geophys. Res., 101, pp. 19237-19244 (1996).

10. Claquin, T., Schulz, M., Balkanski, Y. and Boucher, O. "Uncertainties in assessing radiative forcing by mineral dust", Chem. Phys. Meteorol., 50, pp. 491-505 (1998).

11. Husar, R.B. "The Asian dust events of April 1998", J. Geophys. Res., 106, pp. 18, 317-18, 330 (2001).

12. Prospero, J.M., Ginoux, P. Torres, O., Nicholson, S.E. and Gill. T.E. "Environmental characterization of global sources of atmospheric soil dust identified with the NIMBUS 7 total ozone mapping spectrometer (TOMS) absorbing aerosol product", Rev. Geophys, 40(1), pp. 1002-1023 (2002).

13. Washington, R., Todd, M., Middleton N.J. and Goudie, A.S. "Dust-storm source areas determined by the total ozone monitoring spectrometer and surface observations", Ann. Assoc. Am. Geogr., 93(2), pp. 297-313 (2003).

14. Lu Naimeng, L. and Rongzhang, W. "A convective rainfall estimate technique developed by NSMC of China", Acta. Meteor. Sinica., 14, pp. 225-232 (2000).

15. Bin, C., Peng, Z., Beidou, Z., Rui, J., Zhijuan, Z., Tianhe, W. and Tian, Z. "An overview of passive and active dust detection methods using satellite measurements", J. Meteor. Res., 28(6), pp. 1029-1040 (2014).

16. Ackerman, S.A. "Remote Sensing aerosols using satellite infrared observations", J. Geophys. Res., 102, pp. 17069-17080 (1997).

17. Qu, J.J., Hao, X., Kafatos, M. and Wang, L. "Asian dust storm monitoring combining terra and aqua MODIS SRB measurements", IEEE Geosci. Remote Sens. Lett., 3(4), pp. 484-486 (2006).
18. Legrand, M., Bertrand, J.J. and Desbois, M. "Dust clouds over West Africa: A characterization by satellite data", Ann. Geophys., 3, pp. 777-783 (1985).

19. Roskovensky, J.K. and Liou, K.N. "Differentiating airborne dust from cirrus cloud using MODIS data", Geophys. Res. Lett., 32, pp. 12809-12815 (2005).

20. Zhang, P., Lu, N. and $\mathrm{Hu}, \mathrm{X}$. "Identification and physical retrieval of dust storm using three MODIS thermal IR channels", Global Planet Change, 52, pp. 197-206 (2006).

21. Sehatkashani, S. Kamali, G., Vazifedoust, M. and Bidokhti, A.A. "Dust frequency classification using synoptic meteorological stations data in west and south west of Iran", 1th Int. Conf. on Environ. Crisis and Its Solution, Kish Island, Iran, pp. 23-29 (2013).

22. Bidokhti, A.A. Shariepour, Z. and Sehatkashani, S. "Some climate and meteorological aspects of air pollution in Tehran", U.S.-Iran Symposium on Resilient Cities, USA (2014).

23. Karimi, N., Moridnejad, A., Golian, S., Samani, J.M.V., Karimi, D. and Javadi, S. "Comparison of dust source identification techniques over land in the Middle East region using MODIS data", Can. J. Remote. Sens., 38(5), pp. 586-599 (2012).

24. Hao, X. and Qu, J.J. "Saharan dust storm detection using moderate resolution imaging spectro-radiometer thermal infrared bands", J. Appl. Remote Sens., 1(1), pp. 13-24 (2007).

25. Zhao, X. "Asian dust detection from the satellite observations of moderate resolution imaging spectroradiometer (MODIS)", Aerosol and Air Quality Research, 12, pp. 1073-1080 (2012).

\section{Biographies}

Saviz Sehatkashani received a $\mathrm{PhD}$ in Meteorology from Science and Research Branch of Islamic Azad University, Tehran, Iran. Her research interests include the dust storms classification using their physical characteristics according to MODIS sensor measurements. She has been the weather forecaster at I.R. of Iran Meteorological Organization since 2011, and has had the honor of being the focal point regarding the issues of gender affairs in World Meteorological Organization, working on gender dimensions of weather and climate services with the goal of empowering women to build the climate resilience since 2014. Moreover, she has the honor of cooperation with Intergovernmental Panel on Climate Change (IPCC) as an expert reviewer, and cooperation with World Meteorological Organization (WMO) as an expert in Task Team on the Use of Remote Sensing Data for Climate Monitoring (TTURSDCM).

Majid Vazifedoust received his BSc degree in Irri- 
gation in 1998 from Ferdowsi University of Mashhad, Mashhad, Iran. He accomplished his MSc degree in Irrigation and Drainage in 2001 at the same university. In October 2003, he joined the Soil Physics, Ecohydrology \& Groundwater Management (SEG) Group of Wageningen University and Research Centre (WUR), the Netherlands. He initiated his research by focusing on elements of a real-time agricultural drought assessment system. He attended several postgraduate courses. On November 28, 2007, he obtained his $\mathrm{PhD}$ degree from Wageningen University with a thesis entitled "Development of an Agricultural Drought Assessment System: Integration of Agrohydrological Modeling, Remote Sensing and Geographical Information". He has worked as Assistant Professor at University of Guilan since 2007.

Gholamali Kamali is an Associate Professor in the Department of Meteorology at Science and Research Branch of Islamic Azad University, Tehran, Iran. He received his $\mathrm{PhD}$ degree in the School of Ecology at Science and Research Branch of Islamic Azad University in 1997. He held a postdoctoral position at ITC University, Netherlands. He has more than 35 years of service in several positions such as Chancellor of Research Deputy of I.R. of Iran Meteorological Organization (IRIMO), chancellor of Technical and Operational Deputy of I.R. of Iran Meteorological Organization (IRIMO), as well as faculty member and chancellor of Atmospheric Sciences and Meteorological Research Center (ASMERC) and Dean of Meteorology Department at Science and Research Branch of Islamic Azad University. He has published more than 8 books and 70 papers in the field of agrometeorology and meteorology.

Abbasali Aliakbari Bidokhti is a Professor of Environmental Fluid Mechanics in the Department of Meteorology, Institute of Geophysics, University of Tehran. He received his $\mathrm{PhD}$ in the School of Physics, University of Newcastle upon Tyne, UK, on rotating turbulence flows in 1983. He held a Postdoctoral position in the Department of Engineering at University of Cambridge, working on environmental fluid flows till 1988. Since then, he has been a member of the Institute of Geophysics at University of Tehran. Professor Bidokhti is a member of Institute of Physics, UK, and member of Geophysical Society of Iran. He is editor of a few Journals including: Journal of Applied Fluid Mechanics, Journal of Earth and Space Physics, and Journal of Geophysics of Iran. $\mathrm{He}$ is also a member of the Centre of Excellence of Spatial Analysis of Environmental Hazards, University of Kharazmi. His interests are environmental fluid mechanics concerning meteorology, oceanography, and particularly air pollution over urban areas (dispersion, meteorological conditions creating acute air pollution conditions in urban areas as Tehran). 